\title{
How a Small DNA Virus Uses dsRNA but Not RNAi to Regulate Its Life Cycle
}

\author{
R. Gu, Z. Zhang,* AND G.G. CARMichael \\ Department of Genetics and Developmental Biology, University of Connecticut Health Center, \\ Farmington, Connecticut 06030
}

\begin{abstract}
Mouse polyomavirus contains a circular DNA genome, with early and late genes transcribed from opposite strands. At early times after infection, genes encoded from the early transcription unit are predominantly expressed. After the onset of viral DNA replication, expression of genes encoded from the late transcription unit increases dramatically. At late times, late primary transcripts are inefficiently polyadenylated, leading to the generation of multigenomic RNAs that are precursors to mature mRNAs. These transcripts contain sequences complementary to the early RNAs and downregulate early-strand gene expression by inducing RNA editing. Our recent work leads to a model where the production of the multigenomic late RNAs is also controlled by the editing of poly(A) signals, directed by overlapping primary transcripts.
\end{abstract}

Most DNA viruses exhibit striking temporal regulation of the expression of their genes. Viral genes involved in altering host functions or in regulating viral replication are expressed at early times, whereas virion structural proteins are only expressed at high levels after the onset of viral DNA replication. For some of these viruses (e.g., human adenoviruses and Simian Virus 40) (see Lewis and Manley 1985; Wiley et al. 1993), the temporal regulation of gene expression appears to be at the level of transcription initiation. Work in our laboratory has suggested that an interesting and fundamentally different type of regulation has an important role in the early-to-late switch in gene expression in cells infected with the murine polyomavirus.

Polyomavirus lytically infects mouse cells in tissue culture and is an apparently harmless passenger virus in wild mouse populations. In other rodents, it is tumorigenic and efficiently transforms rat or hamster cells in culture (Tooze 1980). Due to its small genome size and ease of manipulation, it provides us with a good model system for studying not only the molecular biology of cell transformation and tumorigenesis, but also the mechanisms of regulation of eukaryotic gene expression. We have been interested in understanding how viral RNA molecules are made and processed in infected cells. Late viral gene expression has a number of unusual features that have turned out to be useful for helping us to unravel fundamental aspects of RNA synthesis, processing, regulation, and mRNA transport from the nucleus.

\section{GENOME ORGANIZATION}

The polyoma genome is a circular DNA molecule of about 5300 bp. Our laboratory strain, 59RA, is 5327 bp (Ruley and Fried 1983). The genome is divided into

*Present address: Cold Spring Harbor Laboratory, Cold Spring Harbor, New York 11724. "early" and "late" regions, which are expressed and regulated differently as infection proceeds (Fig. 1A) (Griffin and Fried 1975; Kamen et al. 1975, 1980a, b). The early and late transcription units extend in opposite directions around the circular genome from start sites near the unique, bidirectional origin of DNA replication (Crawford et al. 1974; Griffin and Fried 1975). Primary RNA products from the early transcription unit are alternatively spliced to yield three early mRNAs that code for the large $\mathrm{T}$ antigen $(100 \mathrm{kD})$, the middle $\mathrm{T}$ antigen $(56 \mathrm{kD})$, and the small $\mathrm{T}$ antigen $(22 \mathrm{kD})$. Large $\mathrm{T}$ binds to sequences in or near the DNA replication origin region (Gaudray et al. 1981; Pomerantz et al. 1983; Cowie and Kamen 1984; Dilworth et al. 1984) and is involved in the initiation of DNA replication, indirectly in the autoregulation of early-strand RNA levels (Cogen 1978; Farmerie and Folk 1984; Liu and Carmichael 1993), and indirectly in the activation of high levels of expression from the late promoter (Cahill et al. 1990; Liu and Carmichael 1993). The other two early proteins are dispensable for lytic infection, but they are important for cell transformation. Late primary transcripts accumulate after the onset of DNA replication and are also spliced in alternative ways to give mRNAs that code for the three viral structural proteins VP1, VP2, and VP3.

\section{TEMPORAL REGULATION OF GENE EXPRESSION}

Gene expression during lytic infection of permissive mouse cells proceeds in a well-defined temporally regulated manner (Kamen et al. 1975; Beard et al. 1976; Piper 1979). Immediately after infection, RNA from the early transcription unit (E-RNA) begins to accumulate; however, RNA from the late transcription unit (L-RNA) accumulates more slowly. At 12-15 hours after infection, the early-late RNA ratio is about 4 to 1 (see Fig. 1B) (Kamen et al. 1975; Piper 1979; HydeDeRuyscher and Carmichael 1988) and in the presence 
A
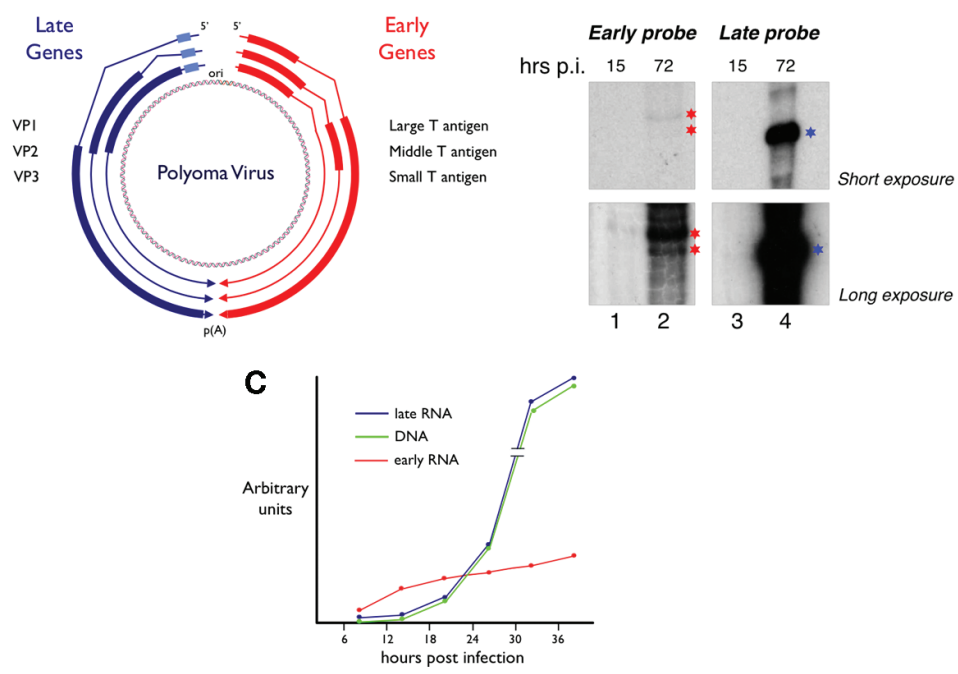

Figure 1. $(A)$ The polyomavirus genome. Early and late genes are transcribed from opposite strands of the genome. (Thick red lines) The exons for the early genes (large, middle, and small $\mathrm{T}$ antigens); (thick blue lines) the exons for the late genes (virus capsid proteins VP1, VP2, and VP3). (B) An example of the early-late switch. Mouse 3 T3 cells were infected with wild-type virus, and RNase protection assays were performed at 15 (an early time) and 72 (a late time) hours after infection, using probes specific for early-strand (red stars) and late-strand (blue stars) mRNAs (Hyde-DeRuyscher and Carmichael 1988). Note that at early times, late-strand RNAs are almost undetectable. (C) A hypothetical representation of a typical polyoma life cycle. Earlystrand RNAs are seen early and accumulate somewhat at late times, but to far lower levels than late-strand RNAs, whose accumulation parallels the accumulation of viral DNA. of DNA replication inhibitors, the ratio is 10 to 1 or higher. At 12-15 hours postinfection, viral DNA replication commences and L-RNA begins to accumulate rapidly, whereas E-RNA accumulates at a slower rate. Thus, there is a dramatic change in the relative abundances of E-RNA and L-RNA; by 24 hours postinfection, the early-to-late RNA ratio is as low as 1 to 50 (Kamen et al. 1975; Piper 1979; Hyde-DeRuyscher and Carmichael 1988). This early-late "switch" is dependent on viral DNA replication; if replication is inhibited, E-RNA accumulates to abnormally high levels with minimal accumulation of L-RNA (Cogen 1978; Heiser and Eckhart 1982; Kamen et al. 1982; Farmerie and Folk 1984; Hyde-DeRuyscher and Carmichael 1988). Figure 1B illustrates the early-late switch using an RNase protection assay, and Figure $1 \mathrm{C}$ presents an idealized depiction of it.

We have generated data that have uncovered unexpected mechanisms about how late genes are activated after the onset of viral DNA replication, as well as how early genes are down-regulated at late times. Furthermore, this work has led to new insights into the mechanism of action of antisense RNA in cells. It has been commonly accepted in the field for many years that the early-late switch is the result of $\mathrm{T}$ antigen repression of the early promoter, coupled with a trans-activation of the late promoter. In fact, there is little experimental support for this notion, and it is not true. We have shown that this temporally regulated switch is not controlled mainly at the level of transcription initiation, but results from changes in transcription elongation and/or RNA stability (Hyde-DeRuyscher and Carmichael 1988, 1990; Liu and Carmichael 1993; Liu et al. 1994). At early times, late-strand transcripts are produced. However, these are inefficiently spliced and exported to the cytoplasm, and they have a short half-life in the nucleus (Fig. 2A) (Hyde-DeRuyscher and Carmichael 1988, 1990; Liu and Carmichael 1993; Liu et al. 1994). At late times, late nuclear RNAs are heterogeneous in size, the result of inefficient polyadenylation and transcription termination, and range from about $2.5 \mathrm{~kb}$ to more than $60 \mathrm{~kb}$ in length (Fig. 2B) (Acheson et al. 1971; Acheson 1976, 1978; Birg et al. 1977; Treisman 1980; Treisman and Kamen 1981). Most late RNA sequences never leave the nucleus as they are removed during mRNA processing and are subsequently degraded (Acheson 1976, 1984).
A

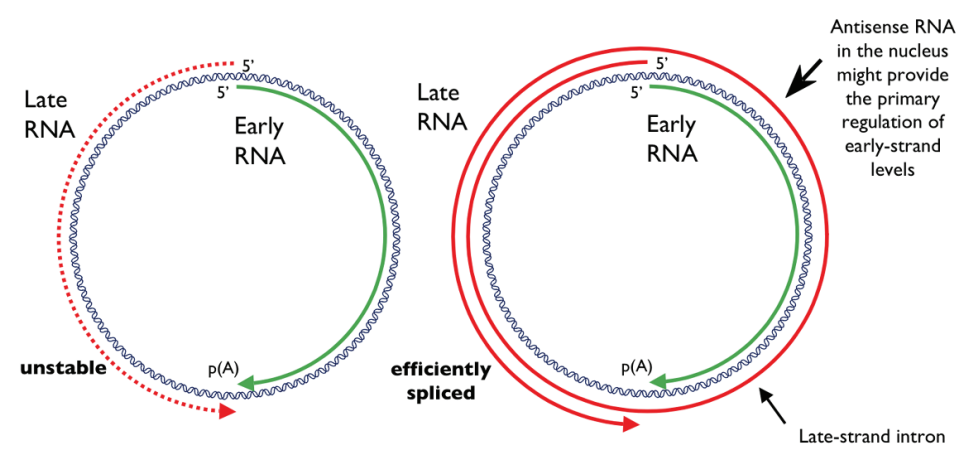

Early phase of infection
Figure 2. Our working model for the early-late switch. See text for details. (A) At early times, both strands are transcribed. However, latestrand RNAs are inefficiently spliced and are unstable in the nucleus. (B) After the onset of viral DNA replication, late polyadenylation/ transcription termination is inefficient, leading to multigenomic primary transcripts. These are efficiently spliced, leading to mature late messages. However, the late pre-mRNAs contain intronic sequences complementary to earlystrand RNAs, and this nuclear antisense RNA may down-regulate early-strand gene expression (Kumar and Carmichael 1997). 
A

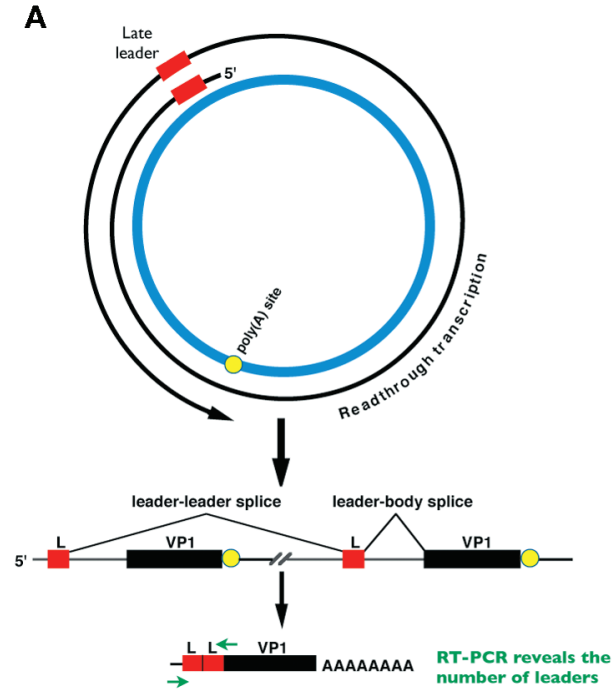

Late-strand pre-mRNA molecules are processed into mature mRNAs using a highly unusual pathway that involves inefficient polyadenylation and ordered splice site selection from precursors containing tandemly repeated introns and exons. Unlike early primary transcripts, late messages contain at their $5^{\prime}$ ends multiple tandem repeats of the 57-base noncoding late leader exon, which appears only once in the viral genome. PremRNA molecules are processed by a pathway that includes the splicing of late leader exons to each other (Fig. 3A). We have shown that each class of late viral message (encoding virion structural proteins VP1, VP2, or VP3) consists of molecules with between 1 and 12 tandem leader units at their $5^{\prime}$ ends (Hyde-DeRuyscher and Carmichael 1990).

The life cycle of the virus appears to be connected to the processing of late pre-mRNAs, and this processing is in turn related to the inefficient use of the late polyadenylation signal. This can be seen in Figure 3B. Note that the great majority of late messages contain multiple tandem leaders at their $5^{\prime}$ ends. This reflects the inefficiency of late polyadenylation, which has been estimated to be about $50 \%$ each time RNA polymerase II traverses the poly(A) signal (Hyde-DeRuyscher and Carmichael 1990; Batt et al. 1994; Batt and Carmichael 1995). Interestingly, however, there is a clear bias against single-leader late mRNAs (Fig. 3B). This is consistent with the model in Figure 2A and the notion that in the absence of leader-to-leader splicing, late premRNAs are relatively unstable in the nucleus. Thus, late mRNAs accumulate in response to leader-to-leader splicing, which is facilitated by inefficient polyadenylation/transcription termination. A major focus of our efforts in the recent past has been to understand how this regulation is controlled.

\section{ANTISENSE REGULATION}

An important contribution to the down-regulation of early RNA levels at late times in infection comes from the multigenomic late-strand transcripts. These RNAs are

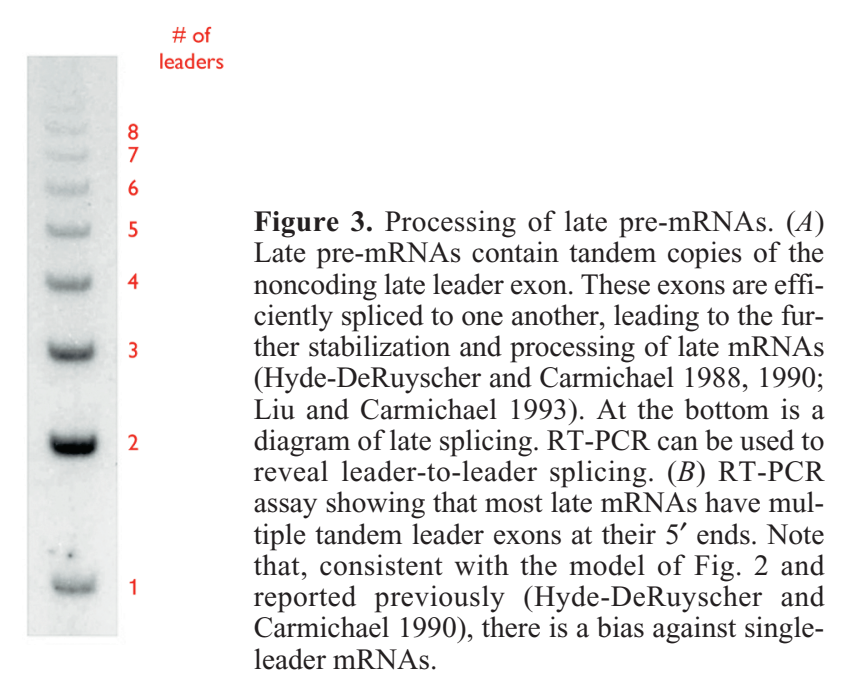

Figure 3. Processing of late pre-mRNAs. $(A)$ exon. These exons are effi(Hyde-DeRuyscher and Carmichael 1988, 1990; Liu and Carmichael 1993). At the bottom is a diagram of late splicing. RT-PCR can be used to reveal leader-to-leader splicing. (B) RT-PCR assay showing that most late mRNAs have multiple tandem leader exons at their $5^{\prime}$ ends. Note that, consistent with the model of Fig. 2 and previously (Hyde-DeRuyscher and leader mRNAs.

antisense to the early transcripts and may anneal with them in the nucleus, forming double-stranded RNA (dsRNA). We have developed several lines of evidence pointing to the importance of antisense regulation to the polyoma life cycle. First, mutants that express lower levels of giant late-strand RNAs always exhibit reciprocally increased early RNA levels (Adami et al. 1989; Liu and Carmichael 1993). Second, dsRNA formation in the nucleus would be expected to lead to editing by the ADAR enzyme. In the nucleus, adenosine residues in dsRNAs can be edited by ADAR to inosines by a process of hydrolytic deamination (Bass 2002). We have shown that this indeed happens in a polyomavirus infection. At late times, early-strand RNAs are extensively edited, with many transcripts exhibiting about $50 \%$ of their adenosines converted to inosines. Furthermore, these promiscuously edited RNAs are quantitatively retained in the nucleus and therefore are not translated into mutant proteins in the cytoplasm (Kumar and Carmichael 1997). Thus, RNA editing dramatically reduces the amount of cytoplasmic translatable early-strand mRNAs at late times. On the other hand, edited late-strand sequences lie within the large intron that is removed and degraded in the nucleus, so that editing does not directly affect latestrand mRNAs.

\section{WHAT IS THE SWITCH THAT ACTIVATES LATE-STRAND SPLICING?}

The polyoma early-late switch is clearly connected to the inefficient use of the late poly(A) signal. But what is the basis of this inefficiency? We have carried out many experiments to uncover the cis-acting sequence(s) in the polyoma late region that confers the temporal regulation of gene expression (Barrett et al. 1991; Liu and Carmichael 1993; Batt and Carmichael 1995; Huang and Carmichael 1996). Curiously, experiments aiming to uncover the "culprit" sequences that regulate the change in late polyadenylation efficiency between early and late times in infection have until recently proved frustrating. The results are summarized in Figure 4. There actually 


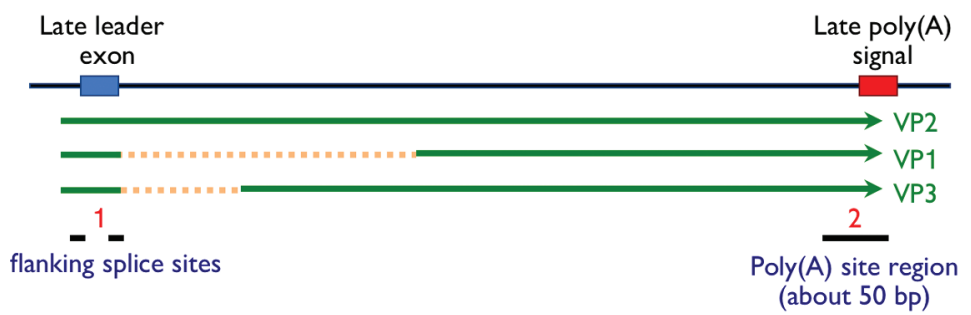

All other regions have been replaced, with no effects on E/L switch
Figure 4. Sequences that might affect the early-late switch have been narrowed to two regions. In previous work from our laboratory (Barrett et al. 1991; Liu and Carmichael 1993; Batt and Carmichael 1995; Huang and Carmichael 1996), all late region sequences except those indicated have been removed or replaced, with no effect on the early-late switch. The splicing signals flanking the late leader exon appear to be important, as well as the poly(A) region. appear to be no clear sequences within the late region of the virus that are essential for the early-late switch. In all of our studies, only two regions could be deleted without dramatic consequences on the switch. The first is the late leader region. Although the leader exon sequence itself is not important, its flanking splice sites must be functional (Adami et al. 1989). This most likely represents the need for leader-to-leader splicing to allow late RNA accumulation at late times.

The second region important for the early-late switch appears to include the poly(A) signal, which cannot be deleted. However, the late poly(A) region also includes elements essential for early-strand gene expression and thus indirectly for viral DNA replication. We next examined this element in greater detail. First, we asked whether the viral poly(A) signal itself is regulated. Our approach was to determine whether it can be replaced by another, unrelated element. We thus chose to mutationally inactivate the late polyadenylation signal while at the same time inserting a functional "synthetic" poly(A) signal (which obeys the known rules for the composition of an efficient processing signal; see Levitt et al. 1989) that contains some unique restriction sites. The resulting virus is called YZ-3 (Fig. 5). Note that this virus has wild-type open reading frames (ORFs) and differs from wild type only in the late poly(A) region. The early poly(A) signal is completely intact. The mutagenesis involved in the construction of YZ-3 was difficult, as the early and late viral poly(A) signals overlap and the ORFs for viral proteins extend to almost the very end of the mRNAs (Fig. 5A). Interestingly, mutant YZ-3 is viable and grows with kinetics indistinguishable from those of our wildtype virus (Z. Liu and G. Carmichael, unpubl.). This mutant exhibits a normal early-late switch when assayed by either RNase protection assays (Fig. 5B) or reverse transcriptase-polymerase chain reaction (RT-PCR) for leader-to-leader splicing (Fig. 5C). The conclusion from these results is that the normal viral late polyadenylation signal appears to be dispensable for viral growth and for the temporal regulation of early and late gene expression. This led to the conclusion that there appears to be no identifiable element in the viral late region that contributes essentially to the early-late switch.

\section{A NEW MODEL FOR THE EARLY-LATE SWITCH}

The above results appeared to rule out the late poly(A) signal itself in the regulation of the early-late switch. However, in this region, we noticed an interesting and previously unappreciated feature of the organization of the viral genome. The early and late polyadenylation signals actually overlap, with the primary transcripts potentially overlapping by at least $45 \mathrm{bp}$ (Fig. 6A). This is the case
A

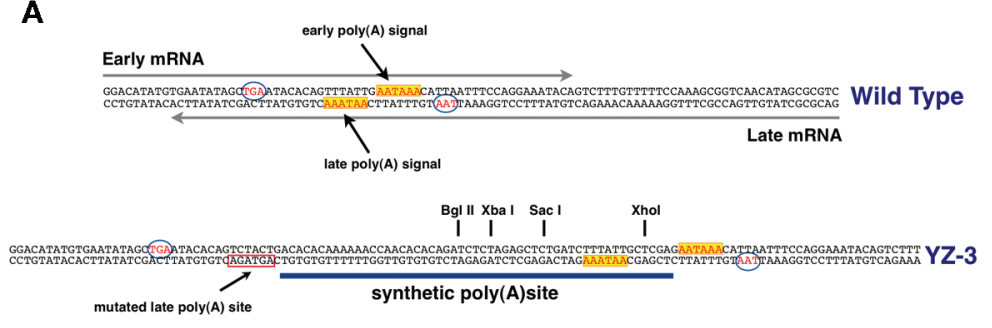

B

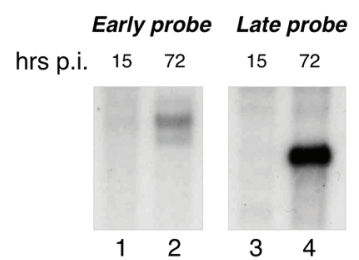

C

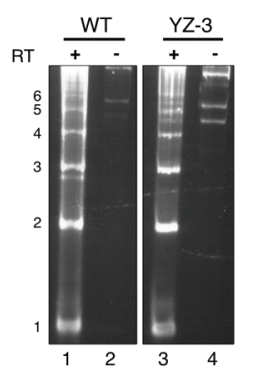

Figure 5. (A) Construction of a mutant virus in which the late polyadenylation signal has been replaced with a synthetic one. Mutant YZ-3 was made as described in several steps. First, a fragment spanning the polyoma wild-type late polyadenylation region was cloned into phage M13mp19. A 100-nucleotide-long synthetic DNA oligonucleotide was then used to simultaneously mutate the viral poly(A) signal and to insert a synthetic poly(A) signal containing several unique restriction enzyme cleavage sites. Following mutagenesis and confirmation by DNA sequencing, the cloned fragment was excised and reinserted into a plasmid containing the entire polyoma genome but lacking this fragment. The resulting viral genome was excised from the plasmid, recircularized by dilute ligation and transfected into mouse NIH$3 T 3$ cells. Virus was harvested and propagated by standard methods. YZ-3 virus grows like wild-type polyoma (data not shown). (B) RNase protection assays as in Fig. 1B show that YZ-3 has a normal early-late switch. (C) RTPCR shows that YZ-3 generates multiple tandem leaders on late mRNAs, just like wild type. 
A

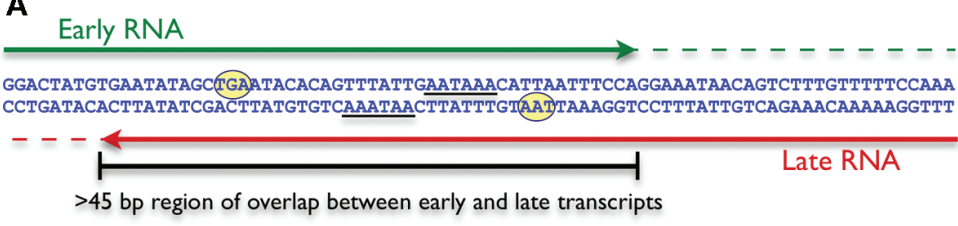

B
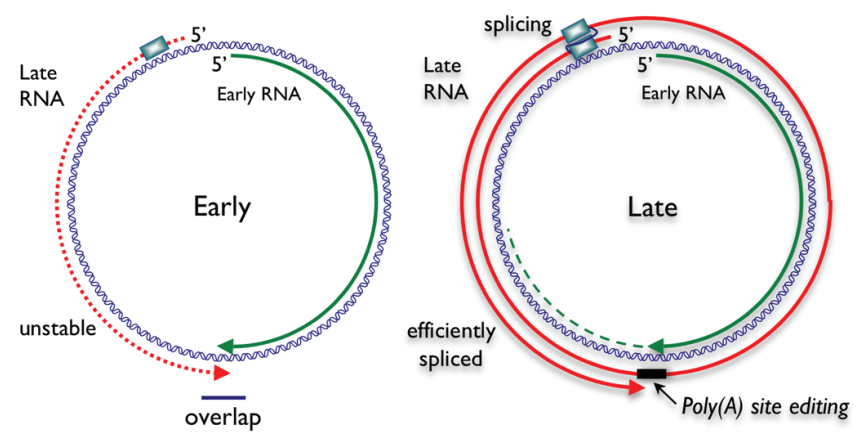

Figure 6. (A) The polyoma early and late polyadenylation signals overlap, with the potential for early-strand and late-strand transcripts to anneal with one another over a region of at least 45 nucleotides. (Dotted lines) Primary transcripts that most likely extend the region of complementarity by an even greater distance. $(B)$ A new model for the early-late switch, in which poly(A)-site editing has a key role. At early times in infection, very little transcript overlap occurs, allowing early mRNAs to preferentially accumulate. At late times, overlapping transcripts become edited in the polyadenylation region, leading to a failure of the $3^{\prime}$-processing machinery to recognize the signals. If the late poly(A) signal is edited, transcription proceeds around the genome, with leader-leader splicing removing the large edited intron and resulting in accumulation of late mRNAs. Productive polyadenylation is thus in competition with editing. At the same time, the early poly(A) signal may also become edited. In this case, however, there is no splicing event that can remove the edited sequences, so editing leads to downregulation of gene expression. for both wild type and YZ-3. Could this overlap be significant? Could overlapping poly(A) signals be regulated by editing? Given what we had already learned about the editing that occurs in the late phase, and that adenosines which are preferred editing targets (those preceded by A's or U's) (Polson and Bass 1994; Kumar and Carmichael 1997) are very rich in this overlap region, it seemed reasonable to hypothesize that early and late strands which overlap at their $3^{\prime}$ ends might serve as substrates for editing that is targeted to the polyadenylation signals. In fact, owing to the known nearest-neighbor preferences for ADAR1 editing, the sequence AAUAAA is almost perfectly suited for editing. In this model, at early times in infection, only very low levels of complementary early-strand and late-strand transcripts would be present in the nucleus, and the vast majority would not anneal with each other in their $3^{\prime}$ regions of complementarity. Early mRNAs would accumulate, and late premRNAs would be degraded. However, after the onset of viral DNA replication, either a critical threshold concentration of sense-antisense RNAs might be reached or conditions might develop so as to facilitate annealing. Duplex regions would be edited by ADAR. This editing would presumably occur in the poly(A) regions of both early-strand and late-strand primary transcripts.

What would be the consequence of poly(A)-site editing for the viral life cycle? Interestingly, such editing might be completely consistent with all known results reported so far; a model for the regulation of the polyoma early-late switch by poly(A)-site editing is presented in Figure 6B. If the late poly(A) signal were to become edited at late times, it would not be recognized by the $3^{\prime}$-end processing machinery, and this would in turn lead to transcriptional readthrough, as is observed. Late-strand readthrough transcripts would be processed by leader-to-leader splicing and leader-to-body splicing of pre-mRNAs that eventually become polyadenylated (see Fig. 3). Splicing would salvage these RNAs and generate functional messengers while at the same time removing the edited portions, which lay within introns. On the other hand, if the early-strand poly(A) signal were edited, early-strand readthrough would also occur, but in this case, the aberrant transcripts could not be resolved by splicing as is the case for latestrand transcripts (there is no $5^{\prime}$-noncoding leader exon) and would therefore be degraded in the nucleus (Maquat and Carmichael 2001). In this scenario, editing and cleavage/ polyadenylation would be in competition with one another to control the viral life cycle. In addition, poly(A)site editing could serve opposite functions, to increase latestrand gene expression and to decrease early-strand gene expression. As the infection proceeds and complementary transcript levels rise, editing might become increasingly prevalent, leading to increasingly higher amounts of late mRNAs but fewer and fewer early mRNAs. One prediction of this new model is that at late times, but not early times, it should be possible to detect direct evidence of editing of viral poly(A) sites. Figure 7 shows one experiment where we have used an RT-PCR approach to demonstrate poly(A)-site editing at late times in polyoma

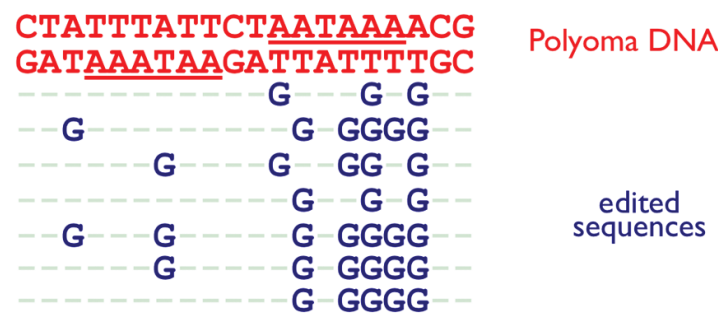

Figure 7. Poly(A) signals are efficiently edited. RT-PCR was used to amplify edited polyoma sequences as described previously (Kumar and Carmichael 1997), and seven edited sequences surrounding the polyadenylation signal (Norbury and Fried 1987) are shown. Note that the sequence AAUAAA is an exceptionally favorable target for ADAR, owing to the wellknown nearest-neighbor preferences for editing (Polson and Bass 1994). 
infection. In additional work to be presented elsewhere, we have carried out a number of additional experiments using other approaches to confirm the importance of poly(A)-site overlap for the viral life cycle.

\section{CONCLUSIONS}

Taken together, the experiments described above lead us to hypothesize that poly(A)-site overlap and editing is a key regulator of the polyoma early-late switch. If true, this surprising finding would identify poly(A)-site editing as a new form of gene regulation, one that has not been reported previously. Since there exist many nuclear transcripts whose $3^{\prime}$ ends overlap those of nearby genes expressed from the opposite DNA strand, it will be of interest to determine whether poly(A)-site editing might also contribute to the regulation of cellular gene expression.

\section{ACKNOWLEDGMENTS}

We are grateful to all members of the laboratory, past and present, who have contributed insights and comments throughout this work. In particular, we acknowledge the contributions of D. Batt, Z. Liu, R. Hyde-DeRuyscher, M. Kumar, and Y. Zhang, and the technical assistance of K. Morris. This work was supported by grants GM066816 and CA045382 from the National Institutes of Health.

\section{REFERENCES}

Acheson N. 1976. Transcription during productive infection with polyoma virus and SV40. Cell 8: 1 .

. 1978. Polyoma giant RNAs contain tandem repeats of the nucleotide sequence of the entire viral genome. Proc. Natl. Acad. Sci. 75: 4754.

. 1984. Kinetics and efficiency of polyadenylation of late polyomavirus nuclear RNA: Generation of oligomeric polyadenylated RNAs and their processing into mRNA. Mol. Cell. Biol. 4: 722.

Acheson N., Buetti E., Scherrer K., and Weil R. 1971. Transcription of the polyoma virus genome: Synthesis and cleavage of giant late polyoma specific RNA. Proc. Natl. Acad. Sci. 68: 223.

Adami G.R., Marlor C.W., Barrett N.L., and Carmichael G.G. 1989. Leader-to-leader splicing is required for the efficient production and accumulation of polyomavirus late mRNA's. J. Virol. 63: 85.

Barrett N.L., Carmichael G.G., and Luo Y. 1991. Splice site requirement for the efficient accumulation of polyoma virus late mRNAs. Nucleic Acids Res. 19: 3011.

Bass B.L. 2002. RNA editing by adenosine deaminases that act on RNA. Annu. Rev. Biochem. 71: 817.

Batt D.B. and Carmichael G.G. 1995. Characterization of the polyomavirus late polyadenylation signal. Mol. Cell. Biol. 15: 4783 .

Batt D.B., Luo Y., and Carmichael G.G. 1994. Polyadenylation and transcription termination in gene constructs containing multiple tandem polyadenylation signals. Nucleic Acids Res. 22: 2811.

Beard P., Acheson N.H., and Maxwell I.H. 1976. Strand-specific transcription of polyoma virus DNA early in productive infection and in transformed cells. J. Virol. 17: 20.

Birg F., Favaloro J., and Kamen R. 1977. Analysis of polyoma viral nuclear RNA by miniblot hybridization. Proc. Natl. Acad. Sci. 74: 3138 .

Cahill K.B., Roome A.J., and Carmichael G.G. 1990.
Replication-dependent transactivation of the polyomavirus late promoter. J. Virol. 64: 992.

Cogen B. 1978. Virus-specific early RNA in 3T6 cells infected by a tsA mutant of polyoma virus. Virology 85: 222.

Cowie A. and Kamen R. 1984. Multiple binding sites for polyomavirus large $\mathrm{T}$ antigen within regulatory sequences of polyomavirus DNA. J. Virol. 52: 750.

Crawford L., Robbins A., and Nicklin P. 1974. Location of the origin and terminus of replication in polyoma virus DNA. J. Gen. Virol. 25: 133.

Dilworth S., Cowie A., Kamen R., and Griffin B. 1984. DNA binding activity of polyoma virus large tumor antigen. Proc. Natl. Acad. Sci. 81: 1941.

Farmerie W.G. and Folk W.R. 1984. Regulation of polyoma virus transcription by large tumor antigen. Proc. Natl. Acad. Sci. 81: 6919.

Gaudray P., Tyndall C., Kamen R., and Cuzin F. 1981. The high affinity binding site on polyoma virus DNA for the viral large-T protein. Nucleic Acids Res. 9: 5697.

Griffin B. and Fried M. 1975. Amplification of a specific region of the polyoma virus genome. Nature 256: 175 .

Heiser W.C. and Eckhart W. 1982. Polyoma virus early and late mRNAs in productively infected mouse 3 T6 cells. J. Virol. 44: 175 .

Huang Y. and Carmichael G.G. 1996. A suboptimal 5' splice site is a cis-acting determinant of nuclear export of polyomavirus late mRNAs. Mol. Cell. Biol. 16: 6046.

Hyde-DeRuyscher R.P. and Carmichael G.G. 1988. Polyomavirus early-late switch is not regulated at the level of transcription initiation and is associated with changes in RNA processing.

Proc. Natl. Acad. Sci. 85: 8993 .
. 1990. Polyomavirus late pre-mRNA processing: DNAreplication-associated changes in leader exon multiplicity suggest a role for leader-to-leader splicing in the early-late switch. J. Virol. 64: 5823.

Kamen R., Favaloro J., and Parker J. 1980a. Topography of the three late mRNA's of polyoma virus which encode the virion proteins. J. Virol. 33: 637.

Kamen R., Lindstrom D.M., Shure H., and Old R.W. 1975. Virus-specific RNA in cells productively infected or transformed by polyoma virus. Cold Spring Harbor Symp. Quant. Biol. 39: 187.

Kamen R., Jat P., Treisman R., Favaloro J., and Folk W.R. 1982. $5^{\prime}$ Termini of polyoma virus early region transcripts synthesized in vivo by wild-type virus and viable deletion mutants. J. Mol. Biol. 159: 189.

Kamen R., Favaloro J., Parker J., Treisman R., Lania L., Fried M., and Mellor A. 1980b. A comparison of polyomavirus transcription in productively infected mouse cells and transformed rodent cell lines. Cold Spring Harbor Symp. Quant. Biol. 44: 189.

Kumar M. and Carmichael G.G. 1997. Nuclear antisense RNA induces extensive adenosine modifications and nuclear retention of target transcripts. Proc. Natl. Acad. Sci. 94: 3542.

Levitt N., Briggs D., Gil A., and Proudfoot N.J. 1989. Definition of an efficient synthetic poly(A) site. Genes Dev. 3: 1019.

Lewis E.D. and Manley J.L. 1985. Control of adenovirus late promoter expression in two human cell lines. Mol. Cell. Biol. 9: 2433 .

Liu Z. and Carmichael G.G. 1993. Polyoma virus early-late switch: Regulation of late RNA accumulation by DNA replication. Proc. Natl. Acad. Sci. 90: 8494.

Liu Z., Batt D.B., and Carmichael G.G. 1994. Targeted nuclear antisense RNA mimics natural antisense-induced degradation of polyoma virus early RNA. Proc. Natl. Acad. Sci. 91: 4258.

Maquat L.E. and Carmichael G.G. 2001. Quality control of mRNA function. Cell 104: 173.

Norbury C.J. and Fried M. 1987. Polyomavirus early region alternative poly(A) site: 3 '-end heterogeneity and altered splicing pattern. J. Virol. 61: 3754 .

Piper P. 1979. Polyoma virus transcription early during productive infection of mouse 3T6 cells. J. Mol. Biol. 131: 399. 


\section{DSRNA REGULATION IN POLYOMA}

Polson A.G. and Bass B.L. 1994. Preferential selection of adenosines for modification by double-stranded RNA adenosine deaminase. $E M B O J$. 13: 5701.

Pomerantz B.J., Mueller C.R., and Hassell J.A. 1983. Polyomavirus large $\mathrm{T}$ antigen binds independently to multiple, unique regions on the viral genome. J. Virol. 47: 600 .

Ruley E. and Fried M. 1983. Sequence repeats in a polyomavirus DNA region important for gene expression. J. Virol. 47: 233.

Tooze J., ed. 1980. Molecular biology of tumour viruses, 2nd edition: DNA tumour viruses. Cold Spring Harbor Laboratory, Cold Spring Harbor, New York.

Treisman R. 1980. Characterization of polyoma late mRNA leader sequences by molecular cloning and DNA sequence analysis. Nucleic Acids Res. 8: 4867.

Treisman R. and Kamen R. 1981. Structure of polyoma virus late nuclear RNA. J. Mol. Biol. 148: 273.

Wiley S.R., Kraus R.J., Zuo F., Murray E.E., Loritz K., and Mertz J.E. 1993. SV40 early-to-late switch involves titration of cellular transcriptional repressors. Genes Dev. 7: 2206. 


\section{$\$_{\text {SSH }}^{\infty}$ \& Cold Spring Harbor Symposia SYMPOSIA On Quantitative Biology}

\section{How a Small DNA Virus Uses dsRNA but Not RNAi to Regulate Its Life Cycle}

R. GU, Z. ZHANG and G.G. CARMICHAEL

Cold Spring Harb Symp Quant Biol 2006 71: 293-299

Access the most recent version at doi:10.1101/sqb.2006.71.017

References This article cites 41 articles, 23 of which can be accessed free at: http://symposium.cshlp.org/content/71/293.full.html\#ref-list-1

License

Email Alerting Receive free email alerts when new articles cite this article - sign up in Service the box at the top right corner of the article or click here. 